\title{
Cotton leaf crumple virus Is a Distinct Western Hemisphere Begomovirus Species with Complex Evolutionary Relationships Indicative of Recombination and Reassortment
}

\author{
A. M. Idris and J. K. Brown
}

Department of Plant Sciences, The University of Arizona, Tucson 85721.

Accepted for publication 1 June 2004.

\section{ABSTRACT}

Idris, A. M., and Brown, J. K. 2004. Cotton leaf crumple virus is a distinct Western Hemisphere begomovirus species with complex evolutionary relationships indicative of recombination and reassortment. Phytopathology 94:1068-1074.

The bipartite DNA genome of Cotton leaf crumple virus (CLCrV), a whitefly-transmitted begomovirus from the Sonoran Desert, was cloned and completely sequenced. The cloned CLCrV genome was infectious when biolistically delivered to cotton or bean seedlings and progeny virus was whitefly-transmissible. Koch's postulates were completed by the reproduction of characteristic leaf crumple symptoms in cotton seedlings infected with cloned CLCrV DNA, thereby verifying the etiology of leaf crumple disease, which has been known in the southwestern United States since the 1950s. Sequence comparisons confirmed that CLCrV has a genome organization typical of yet sufficiently divergent from all other bipartite begomoviruses to justify recognition as a distinct species. Phy- logenetic analyses indicated that CLCrV has a complex evolutionary history probably involving both recombination and reassortment. The relatively low nucleotide sequence identity $(77 \%)$ of the common region shared by the CLCrV DNA-A and DNA-B components and the distinct phylogenetic relationships of each component are consistent with component reassortment. Sequence analyses indicated that the CLCrV DNA-A component was likely derived by recombination among ancestors of two divergent clades (e.g., the Squash leaf curl virus [SLCV] clade and the Abutilon mosaic virus clade) of Western Hemisphere begomoviruses. The CLCrV DNA-B component also may have originated by recombination among an ancestor of the SLCV clade and another distantly related but unknown Western Hemisphere begomovirus.

Additional keywords: Bemisia tabaci, cotton virus, Geminiviridae, Phaseolus, virus evolution.
Cotton leaf crumple virus (CLCrV), a whitefly-transmitted member of the genus Begomovirus (family Geminiviridae), causes a widespread disease of cotton Gossypium hirsutum (L.) in the Sonoran Desert of Arizona (AZ) and Sonora (SON), Mexico $(4,19)$. The disease also occurs in southern California (CA), the Rio Grande Valley of Texas, and Guatemala $(5,7,8,14,17)$. In all instances, the disease was associated with the presence of the sweetpotato whitefly Bemisia tabaci (Genn.) $(4,5,11)$, the only recognized insect vector $(22)$ of begomoviruses $(35,37)$.

Symptoms of the disease are foliar discoloration, leaf crumpling, shortening of internodes, and stunting both in cotton (17) and in experimentally and naturally infected common bean Phaseolus vulgaris (L.) $(11,12)$. Disease severity is dependent upon plant age at time of infection $(4,9,15,46,48)$. Severe outbreaks of cotton leaf crumple disease may be exacerbated by ratooning; a practice in which cotton is pruned and allowed to regrow the following year (10). Efforts to develop disease-resistant cotton varieties have employed cv. Cedix as the source of introgressed genes, and several virus-tolerant lines have been selected $(47,48)$.

Nuclear inclusion bodies, now recognized as a hallmark for viruses of the family Geminiviridae $(1,30,31)$, have been observed in cotton leaves exhibiting typical leaf crumple symptoms (45). Geminate particles have been observed by transmission electron microscopy in purified virus preparations from cotton and bean plants with leaf crumple disease (10). These observations, when taken together with B. tabaci transmission, were considered pro-

Corresponding author: J. K. Brown; E-mail address: jbrown@ag.arizona.edu

Publication no. P-2004-0726-02R

(C) 2004 The American Phytopathological Society visional evidence for geminiviral etiology of the leaf crumple disease (10). Results of serological (42) and DNA sequence $(5,8,34)$ analyses have recently corroborated the etiological hypothesis. Until this report, however, an infectious CLCrV genome had not been cloned or sequenced, and the use of Koch's postulates to verify etiology of leaf crumple disease had not been completed.

Begomoviruses have circular, single-stranded DNA genomes that replicate through a double-stranded DNA (dsDNA) intermediate employing a rolling-circle mechanism (41). To date, all begomoviruses that originated in the Western Hemisphere are bipartite $(35,37)$. Bipartite begomoviral components, referred to as DNA-A and DNA-B, have a common region (CR) of approximately 200 nucleotides (nts) in length that is highly conserved among cognate components of a given species. The CR contains the viral origin of replication (ori), the recognition and binding sites for initiation of replication, and sequences involved in the transcription of certain viral open reading frames (ORFs) $(2,3$, 21,32).

Here, we report cloning of the bipartite genome of CLCrV and demonstrate that the cloned viral components are infectious when biolistically inoculated to cotton and bean seedlings. Also, the phylogenetic relationship of CLCrV with other begomoviral genomes was determined. Results indicate that CLCrV is a distinct viral species with a complex evolutionary history of recombination and reassortment.

\section{MATERIALS AND METHODS}

Virus sources and maintenance. Leaf samples used as source for cloning and sequencing of the viral genome were collected from cotton plants exhibiting typical leaf crumple symptoms (Fig. 
1A) in Casa Grande, Arizona (AZ) and Caborca, Sonora (SON), Mexico in 1991. To establish virus cultures in the greenhouse, the field isolates (CLCrV-AZ and CLCrV-SON) were transferred to healthy (virus-free) cotton seedlings 'Delta Pine' and 'Land Company 90' (DP 90) using adult $B$. tabaci from a virus-free colony of the A (until 1995) or B biotype (1995 onward) (16) maintained in an insect-free greenhouse on the University of Arizona campus since 1988. Since then, virus cultures have been maintained in the greenhouse by serial whitefly transmission, as described (11). Multiple plant samples also were collected from the two aforementioned locations and from symptomatic cotton plants in Mexico (Mexicali, Baja California [BC]) and in the United States (Maricopa and Yuma, AZ; and Imperial Valley, CA).

Cloning of the CLCrV genome. Total DNA was extracted from symptomatic, apical leaves of cotton plants according to the method of Doyle and Doyle (18). RNase-treated total DNA preparations were used as the source of virus template for cloning CLCrV. DNA-A and DNA-B component-specific probes were amplified by polymerase chain reaction (PCR) (38) using total DNA extracts from CLCrV-infected leaves as template and primers pAV2644 and pAC1154 to label amplicons with digoxigenin (DIG) (24). The DNA-A component-specific primers were based on conserved sequences that flank the viral coat protein $(\mathrm{CP})$ ORF, and were expected to yield an $\approx 1,100$-bp amplicon (27). Primers for PCR amplification of the DNA-B component were BV1855 (27) and BC2571 (5'-GGTAATATTATA(A/C/T)CGGATGG-3') and were expected to yield an $\approx 665$-bp amplicon. Several DNA preparations from cotton plants infected with CLCrV$\mathrm{AZ}$ and -SON isolates were screened in a dot blot assay using component-specific probes to identify samples with the highest concentration of viral DNA. Purified DNA preparations were incubated with various restriction endonucleases and resultant products were analyzed by Southern hybridization using standard protocols (39). Because HindIII or SalI appeared to completely linearize the double-stranded form of both CLCrV components, these enzymes were used for cloning. Total DNA $(\approx 20 \mu \mathrm{g})$ from a CLCrV-SON sample was digested with HindIII or SalI. DNA fragments were separated by agarose gel electrophoresis and visualized by ethidium bromide staining to identify linearized viral dsDNA of the expected size (2.4 to $2.8 \mathrm{kbp}$ ). Linearized DNA was eluted from the gel and purified using the GENECLEAN II Kit (BIO 101, Carlsbad, CA). The size-selected DNAs were ligated to the HindIII- or SalI-linearized plasmid, pGEM5zf+ (Promega, Madison, WI), and the ligation mixture was used to transform Escherichia coli, strain DH5 $\alpha$, using a standard protocol (39).

Clones bearing recombinant plasmids containing viral inserts of approximately $2.6 \mathrm{kbp}$ were identified by colony hybridization using DIG-labeled CLCrV-SON DNA-A or DNA-B probes as described (28). Recombinant plasmids containing an apparent fulllength insert of the CLCrV-SON DNA-A (pCLCrV-H25) or DNA$\mathrm{B}$ (pCLCrV-S8) component were selected for further analysis.

Degenerate begomoviral PCR primers were used to amplify an z1,300-nt fragment containing the viral $\mathrm{CP}$ and $\mathrm{CR}$ (27) for CLCrV-AZ, and for 19 additional field isolates from the Sonoran Desert. PCR amplicons were obtained and cloned, and DNA sequences were determined. These sequences were used to design sequence-specific abutting primers AV1153 (5'-GCTAGAAGCTTTGTGGAGAAGCAACGCTTTCCGTA-3') and AC1129 (5'-GTGAGAAGCTTACCTGAACTTCCAAGTCTGGACGACA-3') to PCR amplify a full-length DNA-A component for CLCrV-AZ. Amplicons were cloned in pGEM T-Easy vector (Promega), and recombinants plasmid containing a full-length DNA-A (pCLCrVH1) component was selected for sequencing as described previously (28).

DNA sequencing. Automated, capillary DNA sequencing was performed at the Genomics Analysis and Technology Center, University of Arizona, Tucson. A complete nucleotide sequence was determined for each cloned insert in both orientations, using primer walking with an overlap of at least $\approx 150$ to $200 \mathrm{nts}$. Sequences were compiled using FAKtory, an online program developed by Biotechnology Computing Facility, University of Arizona, which employs Phred, a base-calling algorithm, available from the University of Washington (20). The DNA sequence was determined for CLCrV-SON DNA-A (pCLCrV-H25) and DNA-B (pCLCrV-S8), and for the CLCrV-AZ DNA-A (pCLCrV-H1). The location and size of ORFs were predicted for the apparent fulllength DNA-A and DNA-B components using Editseq (DNASTAR, Madison, WI).

Infectivity of cloned CLCrV-SON components. Recombinant plasmids bearing tandemly repeated copies of the cloned CLCrVSON DNA-A (pCLCrV-H25D) and DNA-B (pCLCrV-S8D) component inserts were constructed in pGEM7zf+ and pGEM5zf+, respectively, as described (41). The tandemly repeated viral clones were delivered to virus-free test plants by biolistic inoculation (29) using $\approx 0.5 \mu \mathrm{g}$ of each tandemly repeated cloned viral DNA component. Common bean 'Red Kidney' and cotton 'DP 90' were used as test plants for infectivity assays. At least four seedlings were inoculated in each of four replicated experiments. Negative controls consisted of noninoculated seedlings, and seedlings biolostically inoculated with water instead of cloned viral DNA. Additional controls included test plants inoculated singly with either the DNA-A or DNA-B component of CLCrV-SON. Test plants were maintained in a whitefly-free greenhouse and monitored for symptom development over 2-weeks postinoculation. Test plants were considered positive for virus infection, based on the development of characteristic disease symptoms (Fig. 1A), and presence of viral DNA in systemically infected leaves as determined by PCR amplification of a 576-bp fragment of the CP ORF (49). Total DNA used as template in PCR assays was extracted according to the method of Doyle and Doyle (18).

Vector transmission of progeny derived cloned CLCrVSON DNA. Adult, nonviruliferous B. tabaci B biotype (16) whiteflies were given a 24-h acquisition access period on symptomatic cotton plants infected with cloned CLCrV DNA-A and DNA-B components. Viruliferous whiteflies (15 to 20) were transferred to and allowed a 48-h inoculation access period on virus-free cotton seedlings (four-leaf stage), after which they were killed by fumigation. Test plants were maintained in a whiteflyproof greenhouse and observed periodically for symptom development for 2 weeks postinoculation. Negative experimental controls included cotton seedlings exposed to nonviruliferous whiteflies and noninoculated cotton seedlings. Four cotton seedlings per treatment were inoculated in each of four replicates.

Phylogenetic analyses of CLCrV-AZ and -SON sequences. The complete nucleotide sequences of the DNA-A and DNA-B components of CLCrV-AZ and -SON isolates were aligned with
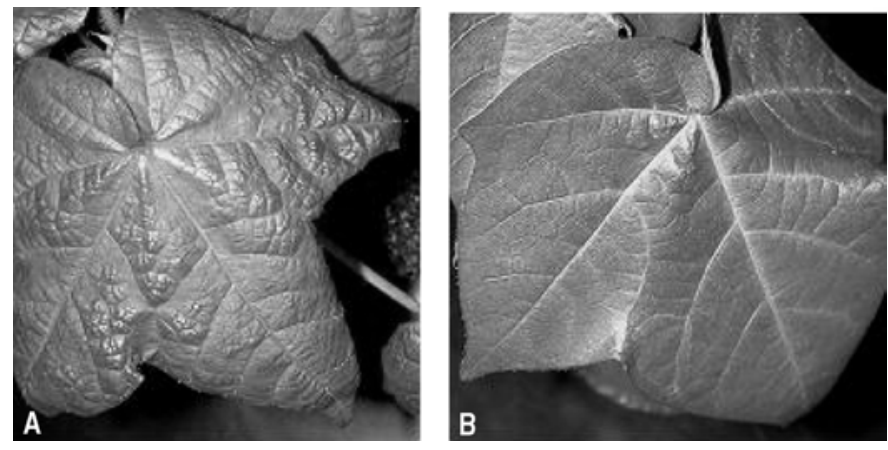

Fig. 1. A, Typical symptoms of Cotton leaf crumple virus (CLCrV) in infected cotton, Gossypium hirsutum (L.) 'Delta Pineland 90'. Seedlings (three- to four-leaf stage) were biolistically inoculated with infectious DNA-A and DNA-B components cloned from CLCrV-infected cotton. B, Healthy (virus-free) cotton leaf. 
the respective sequences for representative begomoviruses available in GenBank (Table 1). Viral sequences were aligned using Clustal W of DNASTAR (Lasergene Software, Madison, WI). The alignment was imported into Sequence Alignment Software (Se-Al v2.0a10, Copyright 1996, A. Rambaut, Zoology Department, University of Oxford). Sequences were manually aligned to maintain in-frame coding regions for ORFs of $\geq 10 \mathrm{kDa}$ in size. Sequence divergence was estimated using distance values calculated for the final alignment by the Clustal W algorithm (44).

Phylogenetic trees were reconstructed using maximum parsimony (MP) and maximum likelihood (ML) methods available in Phylogenetic Analysis Using Parsimony (PAUP*), version 4.0.0b8 (43). For MP, a single most parsimonious tree was sought using a heuristic search method, stepwise addition, and the treebisection-reconnection random branch-swapping options for 500 iterations of bootstrap sampling (10 replicates per iteration). Bootstrap values were calculated using the $>70 \%$ majority rule, and confidence limits were placed at major nodes on the most parsimonious taxonomic reconstruction. ML trees were estimated using the GTR and gamma distribution options, and the SPR branch-swapping algorithm of the heuristic search method, with default settings for all other parameters. The ts:tv ratio employed was two. The analyses assumed no recombination or reassortment in the history of the taxa.

Recombination analysis. Recombination analysis was carried out using GENECONV, a computer algorithm based on Sawyer's statistical tests for detecting gene conversion (40). The command line for this analysis is <GENECONV file_name c/ /g1 -ExpFormat $>$, where $\mathrm{c} /=$ circular DNA, /g1 = a g scale of 1 , and -ExpFormat $=$ exponential format. The analysis compiles all possible recombination events in a prescribed set of aligned sequences, and ascribes a multiple-comparison with corrected probabilities, based on a search for DNA fragments that are identical for different sequences, and which also would be longer than expected by random distribution of polymorphic sites (36). The significance of recombinant fragments identified in the assessment was based on assigned $P$ values for 10,000 permutations. Using this algorithm, recombinant fragments were identified as those having a $P$ value of $<0.05$, based on BLAST-like global scores (40).

\section{RESULTS}

CLCrV DNA clones infectivity and whitefly vector transmission. Cotton (Fig. 1A) and bean seedlings that were co-inoculated with tandemly repeated units of cloned CLCrV-SON DNA$\mathrm{A}$ and DNA-B developed typical disease symptoms, beginning 10 days following biolistic inoculation. Cotton seedlings showed a higher rate of infectivity (16/16 plants; $100 \%)$ compared with that of bean plants ( $9 / 16$ plants; $56 \%)$. The whitefly vector transmitted progeny virus of the cloned components from cotton to cotton with relatively high efficiency (12/16 plants; $75 \%)$. Cotton seedlings inoculated either with the CLCrV-SON DNA-A or

TABLE 1. Geminiviruses used in comparative sequence analyses with their respective GenBank accession numbers

\begin{tabular}{|c|c|c|c|}
\hline \multirow[b]{2}{*}{ Geminivirus } & \multirow[b]{2}{*}{ Acronym } & \multicolumn{2}{|c|}{ GenBank accession number } \\
\hline & & A component & B component \\
\hline Abutilon mosaic virus-West Indies & AbMV & $\mathrm{X} 15983$ & X15984 \\
\hline African cassava mosaic virus-Kenya & ACMV-KE & J02057 & J02058 \\
\hline African cassava mosaic virus-Nigeria & ACMV-NG & X17097 & X17096 \\
\hline Bean calico mosaic virus & BCaMV & AF110189 & FA110190 \\
\hline Bean dwarf mosaic virus & BDMV & M88179 & M88180 \\
\hline Bean golden mosaic virus-Brazil & BGMV & M88686 & M88687 \\
\hline Bean golden yellow mosaic virus-Mexico & BGYMV-MX & AF173555 & AF173666 \\
\hline Bean golden yellow mosaic virus-Puerto Rico & BGYMV-PR & M10070 & U65530 \\
\hline Beet curly top virus & BCTV & M24597 & $\mathrm{NP}^{\mathrm{a}}$ \\
\hline Cabbage leaf curl virus & CaLCV & U65529 & U65530 \\
\hline Cotton leaf curl Alabad virus & CLCuAV & AJ002452 & $\mathrm{NP}$ \\
\hline Cotton leaf curl Gezira virus & CLCuGV & AF260241 & NP \\
\hline Cotton leaf curl Kokhran virus & CLCuKV & AJ002449 & NP \\
\hline Cotton leaf curl Multan virus & CLCuMV & AJ002447 & NP \\
\hline Chino del tomate virus & CdTV & AF226664 & U57458 \\
\hline Hollyhock leaf crumple virus & HLCrV & AY036009 & NP \\
\hline Indian cassava mosaic virus & ICMV & Z24758 & Z24759 \\
\hline Macroptilium mosaic Puerto Rico virus & MaMPRV & AY044133 & AY044134 \\
\hline Macroptilium yellow mosaic Cuba virus & MaYMCV & AJ344452 & $\mathrm{NA}^{\mathrm{b}}$ \\
\hline Macroptilium yellow mosaic Florida virus & MaYMFV & AY044135 & AY044136 \\
\hline Okra enation virus & OkEV & AY036010 & NP \\
\hline Okta yellow vein mosaic virus & OYVMV & AJ002451 & NP \\
\hline Pepper huasteco yellow vein virus & PHYVV & X70418 & X70419 \\
\hline Pepper golden moaic virus-Tamaulipas & PepGMV-TAM & U57457 & AF49227 \\
\hline Potato yellow mosaic virus & PYMV & NC001934 & NC001935 \\
\hline Rhynchosia golden mosaic virus & RhGMV & AF239671 & NP \\
\hline Sida golden mosaic Costa Rica virus & SiGMCRV & X99550 & X99551 \\
\hline Sida yellow vein virus & SiYVV & Y11099 & AJ250731 \\
\hline Sida golden mosaic Honduras virus & SiGMHV & Y11097 & Y11098 \\
\hline Sida golden mosaic Florida virus & SiGMFV & U77964 & U77963 \\
\hline Squash leaf curl virus & SLCV & M38183 & M38182 \\
\hline Tomato golden mosaic virus & TGMV & K02029 & K02030 \\
\hline Tomato leaf curl New Delhi virus-Lucknow & ToLCVNDV-Luc & Y16421 & X89653 \\
\hline Tomato mosaic Havana virus-Quivican & ToMHV-Qui & Y14874 & Y14875 \\
\hline Tomato mottle Taino virus & ToMoTV & AF012300 & $\mathrm{NP}$ \\
\hline Tomato mottle virus & ToMoV & L14460 & L14461 \\
\hline Tomato rugose mosaic virus & ToRMV & NC002555 & AF291706 \\
\hline Tomato yellow leaf curl virus-Israel & TYLCV & X15656 & NP \\
\hline Watermelon chlortic stunt virus-Iran & WmCSV-IR & AJ245652 & AJ245653 \\
\hline Watermelon chlortic stunt virus & WmCSV-SD & AJ245650 & AJ245651 \\
\hline
\end{tabular}

a DNA-B not present (NP) in monopartite species.

b DNA-B sequence of bipartite virus not available (NA). 
DNA-B component, alone, developed no symptoms and neither component was detectable in DNA extracts by PCR (data not shown).

Relatedness of CLCrV isolates. The complete DNA-A sequence for the SON (AF480940) and AZ (AY083350) isolates of CLCrV, and the CLCrV-SON DNA-B component sequence (AF480941) were determined to be 2,630, 2,630, and 2,550 nt, respectively, and sequences were deposited in GenBank and assigned the respective accessions indicated. The two CLCrV DNAA components (AZ, SON) shared $97.9 \%$ nucleotide identity, indicating that they are isolates of the same species. This conclusion is based on the working species definition for begomoviruses, in which distinct species share $<89 \%$ overall nucleotide identity (33). The absence of discernable differences in symptom phenotype for CLCrV isolates from the United States (AZ, CA) and Mexico (BC, SON) (J. K. Brown, unpublished data) also is consistent with a single viral species. Indeed, when the regional variability among several field isolates was determined by examining the coat protein $(C p)$ sequence for isolates from Mexico (Caborca, SON $[n=4]$; and Mexicali, BC $[n=2]$ ) and the United States (Casa Grande [ $n=3$ ], Maricopa $[n=4]$, and Yuma $[n=4]$, AZ; and Imperial Valley, CA $[n=4]$ ) (AF070921, AF335425, AF335426; or unpublished data) (8), the 21 isolates diverged by only 0 to $4 \%$, suggesting that $\mathrm{CLCrV}$ isolates throughout the Sonoran Desert region are quite similar.

Genome organization. The CLCrV genome organization (Fig. 2) was typical of most other bipartite begomoviruses from the Western Hemisphere in having five ORFs of $\geq 10 \mathrm{kDa}$ in size $(32,35)$. The virion-sense strand encoded one ORF (AV1), whereas the complementary-sense strand encoded four ORFs (AC1, $\mathrm{AC} 2, \mathrm{AC} 3$, and AC4). All five ORFs have homologues in other bipartite genomes, suggesting that each CLCrV ORF encodes a protein functioning similarly to their counterpart in other bipartite begomoviruses. A comparison of CLCrV ORFs with those of other begomoviruses is presented in Table 2.

The CR of the CLCrV DNA-A (AZ, SON) and DNA-B (SON) components contained all hallmark sequence elements typically associated with the begomoviral origin of replication and putative promoters for certain viral ORFs $(2,3,21,32)$. Two directly repeated copies of the iterated sequence, GGAGTC, the first of which is recognized by and bound by REP (the gene product of ORF C1) during viral replication (21), were identified in the CR for the DNA-A component (nucleotide coordinates 2530 to 2535 and 2537 to 2542) of both isolates. An inverted copy of the iteron also was identified at DNA-A nucleotide coordinates 2605 to 2600 located between the TATA box and the stem-loop structure of the ori (Fig. 3). The same iteron was similarly arranged in the DNA-B component, suggesting that the components are a cognate pair. However, at $77 \%$ overall shared identity, the CR of DNA-A and DNA-B was surprisingly divergent for a cognate pair (Fig. 3).

Phylogenetic relationships. The ML and MP analyses generated similar phylogenetic reconstructions for either the $\mathrm{CLCrV}$ DNA-A (AZ, SON) or DNA-B (SON) component. Thus, only the results for MP analysis are presented here (Fig. 4A and B). A comparison of the nucleotide identity for the CLCrV DNA-A and DNA-B components with selected Western Hemisphere begomoviruses is shown in Table 3. Phylogenetic comparisons revealed that the closest CLCrV relatives are begomoviral species that group in the large Western Hemisphere clade (35), indicating that CLCrV has a Western Hemisphere origin.

The CLCrV DNA-A component shared overall highest nucleotide identity (72 to $75 \%$ ) with members of the Squash leaf curl virus (SLCV) clade (Table 3) and represents the basal taxon of the SLCV clade (Fig. 4A). Sequence comparisons for the CLCrV DNA-B component indicated that its closest relatives were Abutilon mosaic virus (AbMV) and Bean calico mosaic virus
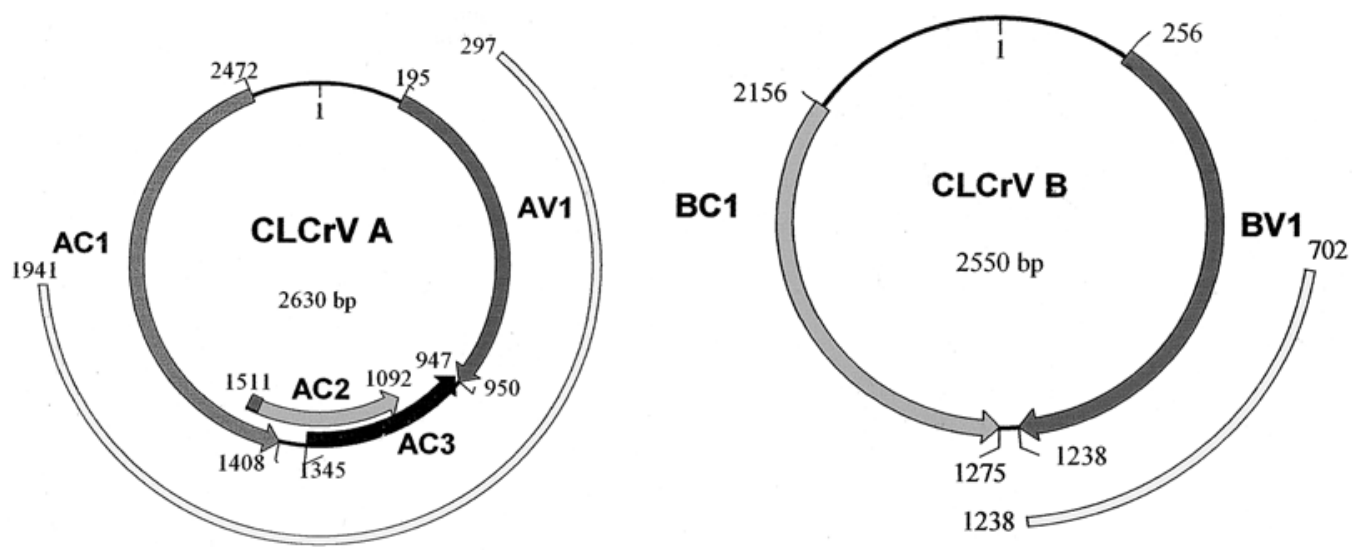

Fig. 2. Map of the Cotton leaf crumple virus (CLCrV) genome indicating locations of predicted recombination fragments. Nucleotide numbering follows the convention for geminiviruses. The locations and orientations of the viral open reading frames (ORFs) on the DNA-A (A) or DNA-B (B) component are shown as (V) for viral strand and (C) for complementary strand. The numbers refer to the start and stop coordinates for each ORF.

TABLE 2. Percent nucleotide and amino acid identities, predicted by Clustal W, for open reading frames of the Sonoran isolate of Cotton leaf crumple virus (CLCrV-SON) compared with the most closely related begomoviruses

\begin{tabular}{|c|c|c|c|c|c|c|}
\hline$\overline{\text { Begomovirus }}$ & AV1 & $\mathrm{AC} 1$ & $\mathrm{AC} 2$ & $\mathrm{AC} 3$ & BV1 & $\mathrm{BC} 1$ \\
\hline AbMV & $82 / 91$ & $70 / 60$ & $86 / 79$ & $85 / 84$ & $70 / 65$ & $77 / 66$ \\
\hline BcaMV & $81 / 92$ & $78 / 80$ & $75 / 65$ & $78 / 75$ & $67 / 65$ & $74 / 77$ \\
\hline PYMV & $81 / 90$ & $68 / 66$ & $86 / 80$ & $87 / 86$ & $69 / 69$ & $79 / 85$ \\
\hline SiGMCRV & $83 / 93$ & $70 / 66$ & $85 / 76$ & $85 / 81$ & $61 / 69$ & $79 / 83$ \\
\hline SiYVV & $83 / 93$ & $68 / 64$ & $83 / 78$ & $82 / 76$ & $70 / 70$ & $77 / 84$ \\
\hline
\end{tabular}

a Sequence not available. 
(BCaMV), at 52 and $57 \%$ shared nucleotide identity, respectively (Table 3). The incongruent placement of the CLCrV DNA-A and DNA-B components on the phylogenetic tree revealed that they probably have had different evolutionary histories (Fig. 4B).

A comparison of the CLCrV ORFs with those of closely related begomoviruses indicated that the CLCrV AC3 ORF shared a maximum percentage nucleotide identity with Potato yellow leaf mosaic virus (PYMV), at 87\% (Table 2). Although the CLCrV AV1 shared $83 \%$ nucleotide identity with a close relative, Sida yellow vein virus (SiYVV), comparisons at the amino acid level indicated that the AV1 sequence for the two viruses was 93\% identical. Similarly, CLCrV AC2 and AC3 ORFs shared high nucleotide identity with SiYVV, at 82 to $83 \%$ and a corresponding high amino acid identity (Table 2). Analysis of CLCrV BV1 and $\mathrm{BC} 1$ indicated that these ORFs share low nucleotide identity with homologous ORFs of their otherwise closest relatives, PYMV, at 69 and 79\%, and Tomato mottle virus (ToMoV), at 70 and 79\%, respectively (Table 2 ).

Evidence for intermolecular recombination. Using Sawyer's gene conversion test (40) and a random permutation level of 10,000 , recombination analysis identified a significant fragment $\left(P\right.$ value $\left.4.83 \mathrm{e}^{-36}\right)(1,597 \mathrm{nt})$ in the DNA-A component for both CLCrV and SiYVV. The fragment occurs between nucleotide coordinates 297 to 1894 (based on CLCrV), and includes large portions of several coding regions (Fig. 2). This 1,597-nt fragment comprises all of the AC2 and AC3 and portions of AV1 and AC1 ORFs. Recombination analysis also identified a significant $\left(P\right.$ value $\left.9.56 \mathrm{e}^{-19}\right)$ fragment of $537 \mathrm{nt}$ in length, shared by the DNA-B component of CLCrV and BCaMV. The fragment, which is located between nucleotide coordinates 702 to 1238 (based on

\section{DNA-A CICAAAACTAGCTCTCAACTICTCTCATATGTTGTGGAGTCTGGAGTCCTMTATATATGTTIACGCTATAGAAGGCATt

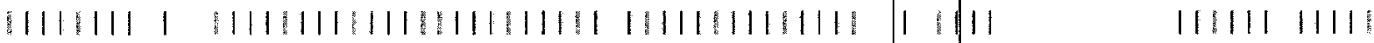 DNA-B CTCAAAAAATGCCTCTCAACTTCTCTCATCTGTTGCGGAGTCTGGAGTCCCATTTATACC-.....-ATAGAAAGCATT}

\section{* \\ DNA-A TGGGGACTCTCCCGGGCCCAC--CATAGGACTCCATACCGCGGCCATCTATATAATATTACTGATGGCCGCGCG

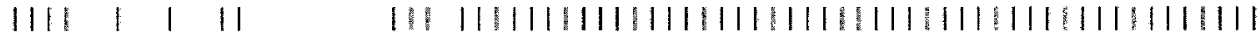 DNA-B GGGGGTATAGCATGGTAATTICACATCGGACTCCATACCGCGGCCATCTATATAATATTACTGATGGCCGCGCG}

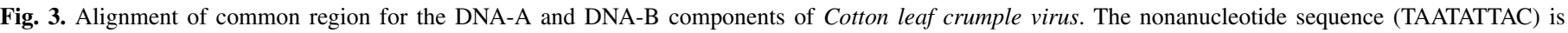

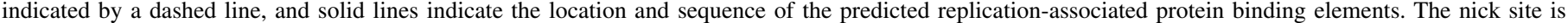

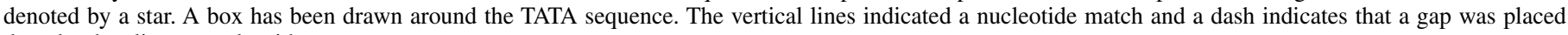
there by the alignment algorithm.
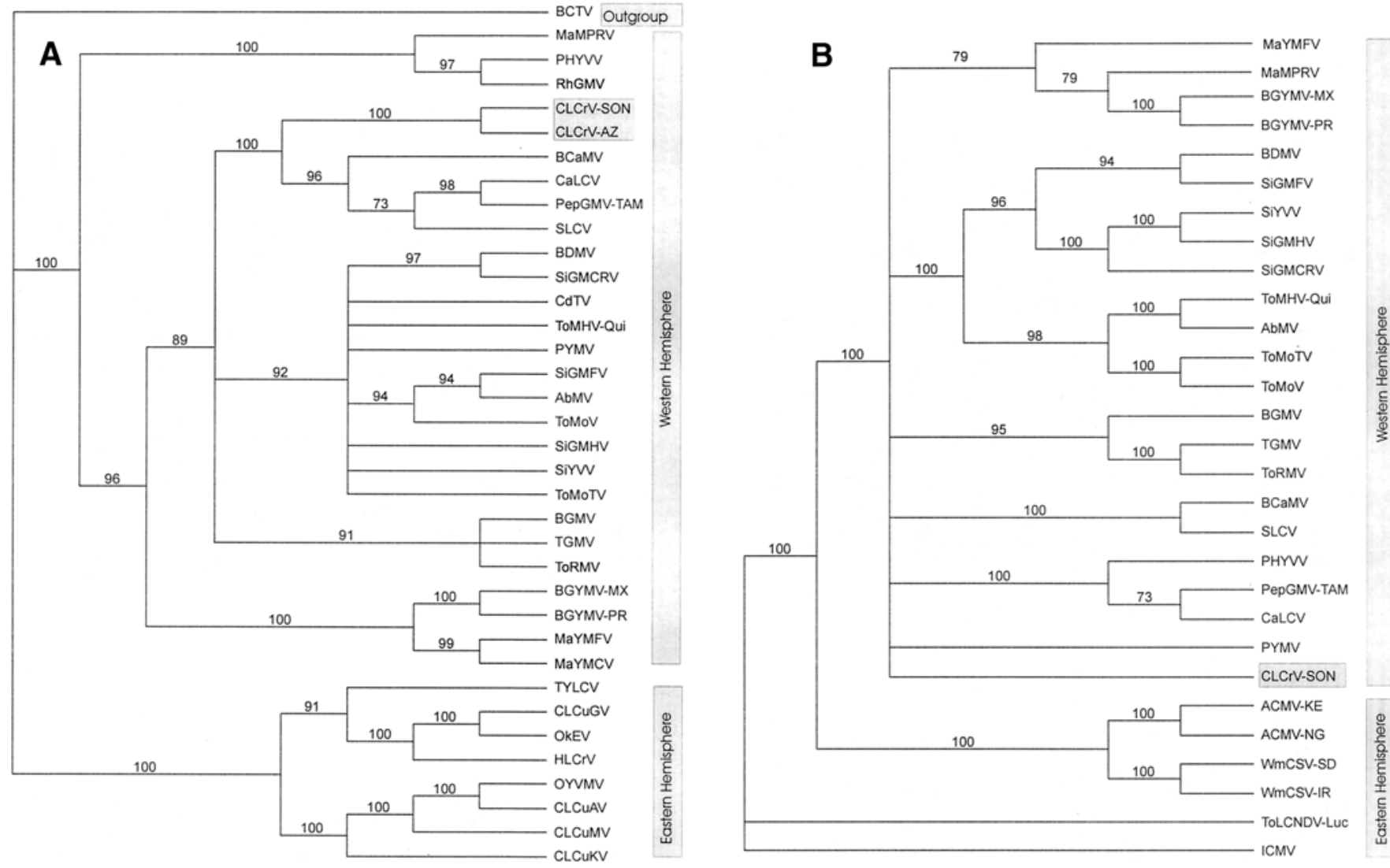

Fig. 4. Phylogenetic trees showing predicted relationships for A, DNA-A or B, DNA-B for Cotton leaf crumple virus (CLCrV) and other well-studied geminiviruses. Trees were reconstructed using a Heuristic search and parsimony method available in PAUP 4.0b version 10 . The vertical and horizontal branch lengths are arbitrary. Bootstrap values at the major nodes indicate percentage scores calculated for 1,000 replicates. The DNA-A component tree was rooted using the Beet curly top virus (BCTV) sequence, and the DNA-B component tree was rooted with the Tomato leaf curl New Delhi virus (ToLCNDV) sequence. 
CLCrV), comprises the $3^{\prime}$ proximal terminus of the BV1 ORF (Fig. 2), which encodes the viral nuclear shuttle protein and is thought to be involved in host range determination (32).

\section{DISCUSSION}

Etiology of cotton leaf crumple disease and Koch's postulates. Biolistic co-inoculation of the cloned CLCrV-SON DNA-A and DNA-B tandemly repeated to cotton and bean produced typical CLCrV symptoms in both hosts, thereby demonstrating Koch's postulates. The subsequent transmission of progeny virus between cotton plants using the B biotype (6) of the whitefly vector indicated that the cloned CLCrV-SON genome was not only competent for replication and movement, but also that the viral $\mathrm{CP}$ is functional for assembly and vector-mediated transmission.

Features of the CR suggest reassortment. The nucleotide sequence identity of CLCrV CR was unusually low at 77\%. This feature makes CLCrV one of the few known begomoviruses for which the CR is not identical, or nearly so $(>90 \%)(2,25,27)$, and strongly suggests that CLCrV genome has undergone reassortment. However, all hallmark sequence elements of the CR (REP binding sites, TATA box and stem-loop structure) were identical and the components able to produce a systemic infection. Thus, we conclude that the cloned viral components are indeed a cognate pair.

Phylogenetic relationships and recombination. Phylogenetic analyses (MP and ML) indicated that the CLCrV DNA-A component grouped with the SLCV clade within the large cluster containing all Western Hemisphere begomoviruses (Fig. 4A; MP tree). In contrast, the CLCrV DNA-B component was positioned uniquely in the polytomy of Western Hemisphere begomovirus species (Fig. 4B), and did not group with any extant clade. The incongruent phylogenies for each of the CLCrV components (Fig. 4A and $\mathrm{B}$ ), together with a highly divergent $\mathrm{CR}$ sequence, suggest that the CLCrV DNA-A and DNA-B components have evolved differently during at least a portion of their history. Further, such a pattern is highly suggestive of intermolecular recombination $(3,13,23,26,36)$. The latter hypothesis also is supported by the intermolecular conversion data, in which a considerable amount of genetic information present in the CLCrV DNA-A component also occurs in SiYVV (AbMV clade) (Fig. 4A), and which also is illustrated by the unusually high amino acid similarity for the AV1, AC2, and AC3 ORFs (Table 2) of these extant viruses. Similarly, the CLCrV DNA-B component contains a fragment of the BV1 ORF that also is found in BCaMV of the SLCV clade. Begomoviral DNA-B ORFs are highly divergent, presumably due to adaptation to different hosts. Thus, even though the DNA-B component is typically unsuitable for establishing clade affiliations (35), sequence comparisons for the cognate DNA-B component often reveal insightful begomoviral diversification patterns.

TABLE 3. Comparison of pairwise nucleotide identity (Clustal $\mathrm{W}$ ) for the DNA-A and DNA-B component of Cotton leaf curl virus (CLCrV-SON) and select well-studied begomoviruses

\begin{tabular}{lcc}
\hline Begomovirus & DNA-A & DNA-B \\
\hline AbMV & 74 & 52 \\
CLCrV-AZ & 98 & NA $^{\mathrm{a}}$ \\
CLCrV-TX & 93 & NA \\
BcaMV & 75 & 57 \\
BDMV & 74 & 52 \\
CaLCV & 74 & 51 \\
PYMV & 71 & 51 \\
SiGMCRV & 72 & 48 \\
SiYVV & 73 & 51 \\
SLCV & 72 & 44 \\
ToMoV & 72 & 52 \\
\hline
\end{tabular}

a Sequence not available.
Because the closest relatives of CLCrV DNA-A are extant members of the SLCV clade, one may speculate that the ancestral CLCrV arose as a result of recombination between members of SLCV and AbMV clades, perhaps as a virus of a Phaseolus species. We hypothesize that the CLCrV DNA-A and DNA-B backbone (namely, the CR) would most likely have derived from an SLCV ancestor, with the capacity to infect bean. Such a co-association in bean of the CLCrV ancestor with a BCaMV-like virus would have been relatively straightforward and could feasibly then have resulted in the initial recombination event, during which the CLCrV ancestor acquired the 3 ' proximal portion of the BV1 ORF from the BCaMV-like virus. This model is compatible with evidence that CLCrV shares its closest nucleotide sequence affinities with members of the AbMV and SLCV clades, which herein, we hypothesize represent the ancestral lineages of the CLCrV genome.

Recombination analyses revealed that the CLCrV genome has acquired sequences from at least three (or more) different begomoviral species, representing three extant and distinct Western Hemisphere lineages. Thus, CLCrV may be a unique double (or more) recombinant that likely also underwent intermolecular reassortment. In this model, portions of the CLCrV genome (both components) are derived from an ancestral SLCV lineage (of which the genome(s) for such a "nonrecombined" ancestor may no longer exist). Analysis of the DNA-B clearly indicates that it is derived from two extant Western Hemisphere lineages, namely those of PYMV and BCaMV, within the AbMV and SLCV clades, respectively. Further, the ancestral cognate DNA-A component (for the extant DNA-B, minus the BCaMV-like BV1 sequence) is unknown and may be extinct. Indeed, there is no evidence at this time for an extant, cognate CLCrV DNA-A-like component, minus the SiYVV contribution. However, detailed studies of begomoviruses of uncultivated plants now underway throughout the Americas, may very well reveal additional begomoviral sequences that will shed new light on the evolution of CLCrV.

\section{ACKNOWLEDGMENTS}

This study was partially supported by grants to the J. K. Brown from Cotton Incorporated, the Common Fund for Commodities-Cotton, and the International Cotton Advisory Council.

\section{LITERATURE CITED}

1. Aboubzid, A. M., Barth, A., and Jeske, H. 1988. Immunogold labeling of Abutilon mosaic virus in ultrathin sections of epoxy resin embedded leaf tissue. J. Ultrastruct. Mol. Structure Res. 99:38-47.

2. Arguello-Astorga, G. R., Guevara-Gonzalez, R. G., Herrera-Estrella, L. R., and Rivera-Bustamante, R. F. 1994. Geminivirus replication origins have a group-specific organization of iterative elements: A model for replication. Virology 203:90-100.

3. Bisaro, D. M. 1996. Geminivirus DNA replication. Pages 833-854 in: DNA Replication in Eukaryotic Cells. Cold Spring Harbor Laboratory, Cold Spring Harbor, NY.

4. Brown, J. K. 1992. Virus diseases of cotton. Pages 275-330 in: Cotton Diseases. R. J. Hillocks, ed. Commonw. Agric. Bur. Int., Oxon, UK.

5. Brown, J. K. 1998. Global diversity and distribution of whitefly-transmitted geminiviruses of cotton. Pages 155-161 in: Proceeding of 1998 Beltwide Cotton Conference. National Cotton Council of America, Memphis, TN.

6. Brown, J. K., Frohlich, D. R., and Rosell, R. C. 1995. The sweetpotato/silverleaf whiteflies: Biotypes of Bemisia tabaci (Genn.), or a species complex? Annu. Rev. Entomol. 40:511-534.

7. Brown, J. K., and Idris, A. M. 2002. Cotton leaf crumple virus is the first member of a previously undiscovered phylogenetic group of Western Hemisphere begomoviruses. (Abstr.) Phytopathology 92(suppl.):S38.

8. Brown, J. K., Idris, A. M., Torres-Jerez, I., Banks, G. K., and Wyatt, S. D. 2001. The core region of the coat protein gene is highly useful for establishing the provisional identification and classification of begomoviruses. Arch. Virol. 146:1581-1598.

9. Brown, J. K., Mihail, J. D., and Nelson, M. R. 1987. The effects of cotton leaf crumple virus on cotton inoculated at different growth stages. Plant Dis. 71:699-703. 
10. Brown, J. K., and Nelson, M. R. 1984. Geminate particles associated with cotton leaf crumple. Phytopathology 74:987-990.

11. Brown, J. K., and Nelson, M. R. 1987. Host range and vector relationships of cotton leaf crumple virus. Plant Dis. 71:522-524.

12. Brown, J. K., Nelson, M. R., and Lambe, R. C. 1986. Cotton leaf crumple virus transmitted from naturally infected bean from Mexico. Plant Dis. 70:981.

13. Brown, J. K., Ostrow, K. M., Idris, A. M., and Stenger, D. C. 1999. Biotic, molecular, and phylogenetic characterization of Bean calico mosaic virus, a distinct Begomovirus species with affiliation in the Squash leaf curl virus cluster. Phytopathology 89:273-280.

14. Brown, J. K., Palmieri, M., Doyle, M. M., Idris, A. M., and Martyn, R. D. 2002. Diversity of begomoviruses from vegetable, cotton and, weeds in Guatemala and Honduras by viral coat protein sequence analysis. (Abstr.) Phytopathology 92(suppl.):S116.

15. Butler, G. D., Jr., Brown, J. K., and Henneberry, T. J. 1986. Effect of cotton seedling infection by cotton leaf crumple virus on subsequent growth and yield. J. Econ. Entomol. 79:208-211.

16. Costa, H. S., and Brown, J. K. 1991. Variation in biological characteristics and in esterase patterns among populations of Bemisia tabaci (Genn.) and the association of one population with silverleaf symptom development. Entomol. Exp. Appl. 61:211-219.

17. Dickson, R. C., Johnson, M. M., and Laird, E. F. 1954. Leaf crumple, a virus disease of cotton. Phytopathology 44:479-480.

18. Doyle, J. J., and Doyle, J. L. 1987. A rapid DNA isolation procedure for small quantities of fresh leaf tissue. Phytochem. Bull. 19:11-15.

19. Erwin, D. C., and Meyer, R. 1961. Symptomatology of the leaf crumple disease in several species and varieties of Gossypium and variations of causal virus. Phytopathology 51:472-477.

20. Ewing, B., Hillier, L., Wendl, M. C., and Green, P. 1998. Base calling of automated sequencer traces using Phred. I. Accuracy assessment. Genome Res. 8:175-185.

21. Hanley-Bowdoin, L., Settlage, S. B., Orozco, B. M., Nagar, S., and Robertson, D. 1999. Geminiviruses: Models for plant DNA replication, transcription, and cell cycle regulation. Crit. Rev. Plant Sci. 18:71-106.

22. Harrison, B. D. 1985. Advances in geminivirus research. Annu. Rev. Phytopathol. 23:55-82.

23. Hill, J. E., Strandberg, J. O., Hiebert, E., and Lazarowitz, S. G. 1999. Asymmetric infectivity of pseudorecombinants of cabbage leaf curl virus and squash leaf curl virus: Implications for bipartite geminivirus evolution and movement. Virology 250:283-292.

24. Holtke, H. J., Sagner, G., Kessler, C., and Schmitz, G. 1992. Sensitive chemiluminescent detection of digoxigenin-labeled nucleic acids: A fast and simple protocol and its applications. Biotechniques 12:104-113.

25. Hou, Y. M., and Gilbertson, R. L. 1996. Increased pathogenicity in a pseudorecombinant bipartite geminivirus correlates with intermolecular recombination. J. Virol. 70:5430-5436.

26. Hou, Y. M., Paplomatas, E. J., and Gilbertson, R. L. 1998. Host adaptation and replication properties of two bipartite geminiviruses and their pseudorecombinants. Mol. Plant-Microbe Interact. 11:208-217.

27. Idris, A. M., and Brown, J. K. 1998. Sinaloa tomato leaf curl geminivirus (STLCV): Biological and molecular evidence for a new subgroup III virus. Phytopathology 88:548-557.

28. Idris, A. M., Hiebert, E., Bird, J., and Brown, J. K. 2003. Two newly described begomoviruses of Macroptilium lathyroides and common bean. Phytopathology 93:774-783.

29. Idris, A. M., Smith, S. E., and Brown, J. K. 2001. Ingestion, transmission, and persistence of Chino del tomate virus (CdTV), a Western Hemisphere begomovirus, by Old and New Word biotypes of the whitefly vector Bemisia tabaci. Ann. Appl. Biol. 139:145-154.

30. Jeske, H. 1986. The detection of the abutilon mosaic virus depends on the experimental daytime. J. Phytopathol. 115:243-256.

31. Kim, K. S., Bird, J., Rodriguez, R. L., Martin, E. M., and Escudero, J. 1986. Ultrastructural studies of Jatropha gossypifolia infected with jatropha mosaic virus, a whitefly-transmitted geminivirus. Phytopathology 76:80-85.

32. Lazarowitz, S. G. 1992. Geminiviruses: Genomes structure and gene function. Critical Rev. Plant Sci. 11:327-349.

33. Mayo, M. A., and Pringle, C. R. 1998. Virus taxonomy-1997. J. Gen. Virol. 79:649-657.

34. Nadeem, A., Weng, Z., Nelson, M. R., and Xiong, Z. 1997. Cotton leaf crumple virus and cotton leaf curl virus are distantly related geminiviruses. Mol. Plant Pathol. Online Publication no. 1997/0612nadeem.

35. Padidam, M., Beachy, R. N., and Fauquet, C. M. 1995. Classification and identification of geminiviruses using sequence comparisons. J. Gen. Virol. 76:249-263

36. Padidam, M., Sawyer, S., and Fauquet, C. M. 1999. Possible emergence of new geminiviruses by frequent recombination. Virology 265:218-225.

37. Rybicki, E. P. 1994. A phylogenetic and evolutionary justification for three genera of Geminiviridae. Arch. Virol. 139:49-77.

38. Saiki, R. K., Scharf, S., Faloona, F., Mullis, K. B., Horn, G. T., Erlich, H. A., and Arnheim, N. 1985. Enzymatic amplification of B-globin genomic sequences and restriction site analysis for diagnosis of sickle cell anemia. Science 230:1350-1354

39. Sambrook, J., Fritsch, E. F., and Maniatis, T. 1989. Molecular Cloning: A Laboratory Manual. Cold Spring Harbor Laboratory, Cold Spring Harbor, NY.

40. Sawyer, S. 1989. Statistical tests for detecting gene conversion. Mol. Biol. Evol. 6:526-538.

41. Stenger, D. C., Revington, G. N., Stevenson, M. C., and Bisaro, D. M. 1991. Replicational release of geminivirus genomes from tandemly repeated copies: Evidence for rolling-circle replication of a plant viral DNA. PNAS 88:8029-8033.

42. Swanson, M. M., Brown, J. K., Poulos, B. T., and Harrison, B. D. 1992. Genome affinities and epitope profiles of whitefly-transmitted geminivirus from the Americas. Ann. Appl. Biol. 121:285-296.

43. Swofford, D. L. 1998. PAUP*. Phylogenetic analysis using parsimony (*and other methods). Version 4. Sinauer Associates, Sunderland, MA.

44. Thompson, J. D., Gibson, T. J., Plewniak, F., Jeanmougin, F., and Higgins, D. G. 1997. The CUSTALX windows interface: Flexible strategies for multiple sequence alignment aided by quality analysis tools. Nucleic Acid Res. 25:4876-4882.

45. Tsao, P. W. 1963. Intranuclear inclusion bodies in the leaves of cotton plants infected with leaf crumple virus. Phytopathology 53:243-244.

46. Van Schaik, P. H., Erwin, D. C., and Garber, M. J. 1962. Effects of time of symptom expression of the leaf-crumple virus on yield and quality of fiber of cotton. Crop Sci. 2:275-277.

47. Wilson, F. D., and Brown, J. K. 1991. Inheritance of resistance to cotton leaf crumple virus in cotton. J. Hered. 82:508-509.

48. Wilson, F. D., Brown, J. K., and Butler, G. D., Jr. 1990. Reaction of cotton cultivars and lines to cotton leaf crumple virus. J. AZ-NV Acad. Sci. 23:7-10.

49. Wyatt, S. D., and Brown, J. K. 1996. Detection of subgroup III geminivirus isolates in leaf extracts by degenerate primers and polymerase chain reaction. Phytopathology 86:1288-1293. 